\title{
AGRESIVIDAD Y DESTRUCTIVIDAD: UNA CALA EN LA HISTORIA DE LA FILOSOFIA
}

AbELARDo Villegas

Facultad de Filosofia y Letras Universidad Nagional Autónoma de Méxioo

Una de las principales cuestiones que se plantea el historiador de la filosofía es la de averiguar qué partes de la filosofía o de un filosofema particular están determinadas por el medio social, histórico y aun físico en el que está inserto el filósofo y qué partes están determinadas o condicionadas por la dinámica misma de la filosofía, por sus necesidades teóricas e, incluso, por su tradición. Esta cuestión ha sido arduamente discutida proporcionándose una variedad de respuestas, algunas de ellas bastante extremosas: a veces se piensa que la estructura de la filosofía tiene sólo una explicación únicamente en factores extrínsecos a ella, fundamentalmente sociales; $y$ a veces se piensa que unas filosofías van dando lugar a otras a fuerza de puras necesidades lógicas.

Pienso intervenir en esta discusión, pero no de manera especulativa sino mediante el análisis de un ejemplo. Claro está que el ejemplo ha sido seleccionado deliberadamente para mostrar la cuestión en sus muy complejas facetas. Además - me lo tendrán que perdonar los participantes de este coloquio - se tratará de un filosofema formulado por alguien que no es filósofo profesional. Pero no se alarmen, se trata de uno de los etólogos más brillantes de nuestro tiempo, de Konrad Lorenz. $\mathrm{Y}$ es que, a pesar de todos los pruritos de pureza de la filosofía, como conocimiento que es de los primeros principios, tiene que dialogar con otras áreas del conocimiento en las que esos principios se prueban. El gremio aristocrático de los filósofos tiene que dirigirle la palabra a los otros, porque los otros no sólo se dirigen a ellos sino que los increpan y los interrogan.

Pero se trata de un filosofema, casi de una increpación que un etólogo hace a los filósofos. Lo enunciaré muy escuetamente y luego, para examinar sus condicionantes, haré un desplazamiento horizontal hacia la sociedad y unas calas de profundidad en la historia de la filosofia. Pero antes una advertencia: he hablado de factores determinantes, pero qui- 
zá sea mejor utilizar la palabra condicionante. Porque se trata de factores que condicionan la posibilidad de tal o cual filosofía o de tal o cual filosofema, pero que no los determinan necesariamente, por la sencilla razón de que unos mismos factores condicionantes condicionan más de una filosofía.

Konrad Lorenz en su libro Sobre la agresión: el pretendido mal sostiene que la humanidad contemporánea está a punto de-autodestruirse porque hay un desface en'tre la celeridad con que se transforma el mundo histórico, lleno de peligros, y el sistema de los instintos que nos ha permitido sobrevivir hasta ahora. La celeridad histórica no permite, o permite mal, la adaptación biológica, que es lenta. Es un desface entre el tiempo histórico y el tiempo biológico. Ello se debe a la razón humana: "el pensamiento conceptual y la palabra modificaron toda la evolución del hombre al lograr algo que es equivalente a la herencia de los caracteres adquiridos". Cuando un hombre inventa el arco y la flecha, toda la comunidad hereda el conocimiento del empleo de estas armas y las dominan como si se tratara de un órgano de su cuerpo. Así, con los instrumentos inventados puede efectuarse, en el curso de una o dos generaciones, un proceso de adaptación ecológica que en la evolución normal, sin el concurso del pensamiento conceptual, hubiera requerido un período de tiempo de escala muy diferente y mucho mayor. "Nada tiene, pues, de sorprendente que la evolución de los instintos sociales $\mathrm{y}$, cosa aún más importante, las inhibiciones sociales, no hayan podido avanzar a la par del desarrollo que el acrecentamiento de la cultura trasmitida por tradición, y principalmente del adelantamiento material, ha impuesto a la sociedad humana." 1

A esto hay que añadir, para que quede inteligible, dos precisiones. Una, que dentro del sistemas de los instintos que permite la supervivencia animal y humana, el de la agresividad cumple un papel central, también de supervivencia, porque no es completamente destructivo sino que posee una serie de resortes inhibitorios que lo median y regulan. $Y$ otra, es la creencia de Lorenz en que la socialidad moral no es producto de la razón. Entendiendo a Kant a su manera, considera que el imperativo categórico no puede fundar una convivencia moral porque "parece difícil creer que un hombre se abstendría de realizar tal o cual acción a que una inclinación natural le empuja tan sólo porque se diera cuenta de que su realización implicaría una contradicción lógica". "En realidad, la comprensión racional completa de las consecuencias de un acto y de la firmeza lógica de sus premisas jamás tendría por resultado un imperativo ni una prohibición si no le proporcionara motivación

I Konrad Lorenz, Sobre la agresión: el pretendido mal. Siglo XXI Editores, M仓xico, 1976, p. 263. 
alguna fuente de energía emocional, o sea instintiva." 2 En realidad los instintos sociales y amorosos son prehumanos y hacen posible la sociedad animal; ellos le proporcionan fuerzas y energía a las razones de la razón.

Estas son algunas de las conclusiones a que llega Lorenz después de examinar minuciosamente la agresividad animal. Se trata del procedimiento peculiar de la etología que analiza la conducta animal para proporcionar claves de la conducta humana.

Lorenz postula la idea de que a las razones que se dan para impedir una catástrofe mundial deben añadirse procedimientos que facilitan la adaptación biológica de supervivencia a esta coyuntura histórica. Es semejante coyuntura histórica la motivación social de estas conclusiones. Los hombres siempre se han destruido unos a otros. Ya el hombre de Pekin con hachas rudimentarias mataba a sus semejantes y los engullia. Pero ahora, por primera vez, es posible una masacre total por medios artificiales; y lo que suscita este tipo de reflexiones es la evidencia de que una hecatombe total no conviene a nadie, no resultaría en el triunfo de ningunos intereses, ni económicos ni políticos. El juego de intereses puede explicar y justificar la amenaza de la hecatombe, aun la proposición de una hecatombe limitada o limpia, pero el hecho mismo, del cual siempre estamos al borde, no puede estar explicado o justificado de esa manera. Pero sobre todo no es necesario abundar, se trata de una interpretación de las circunstancias sociales como factor condicionante de una idea y suscitador de la misma.

El problema está en su especificidad. ¿Por qué hemos venido a dar al neodarwinismo? $\mathrm{Y}$ no sólo yo en particular sino también un público muy amplio. Una cala en la historia de la filosofía nacional puede proporcionar explicaciones. Cuando menos la de mi caso personal. En la década de los cincuentas, tanto el existencialismo alemán como el francés proporcionaban una ontología del ser del hombre. José Gaos subra. yaba las palabras de Heideger en el sentido de que su filosofía no era una antropología filosófica sino una ontología fundamental, una analítica del ser y no del hombre, complicada, claro está, con una del ser del hombre. Y una situación parecida se presentaba en El Ser y la nada de Sartre. En la medida en que se preguntaban por el ser desde el horizonte del ser del hombre, abundaban en fịnos análisis sobre éste. En perspectiva, ahora considero que esos análisis mostraban fenómenos empíricos, pero hipostatizados, expresados en términos de ser, lo que obligaba a un lenguaje especial que a veces era una verdadera jerigonza. En este manejo de lo ontológico se perdía lo que hay de natural, de biológico en el hombre. Además, la famosa temporalidad ontológica no

2 Ibid., p. 275. 
acababa de guardar sus distancias con la temporalidad psicológica. Por contraste, el rescate de lo natural en el hombre era un imperativo que se desprendía de los excesos de la ontología.

Algo parecido ocurría con el historicismo de Dilthey y de Ortega. Si el hombre era pura historicidad, ¿qué ocurría con su parte natural? ¿También lo biológico quedaba contagiado de historicidad? Este cambio heraclitano incesante, sin progreso, sin regularidad o ley permanente, ¿también explicaba la animalidad de que había hablado Aristóteles? Y, a su vez, la animalidad, ¿no tenía nada que ver con la historia? Aquí nadie respondió a esas preguntas. Pero a mi me parecía evidente que en la vigencia del historicismo y del existencialismo, el ninguneo de lo biológico, por así decirlo, su nadificación, la subsunción de todo en la temporalidad, incluyendo a la razón, obligaban a revisar otra vez el compuesto aristotélico de la animalidad racional.

Pero la cosa no era sencilla - y aquí va la otra cala-, también el concepto de razón se eclipsaba. No sólo estaba subsumida en la temporalidad, en ciertas interpretaciones del marxismo era epifenómeno de las estructuras económicas, el conductismo negaba su existencia y el neoconductismo la concebía como un subproducto de la acción. Nietzsche la consideraba fabricante de fábulas trascendentes y postulaba a los instintos como los verdaderos motores de la vida. Finalmente Freud efectúa una nueva revolución copernicana y sostiene que la mayor parte de la vida psíquica no sólo escapa al control de la razón sino de la conciencia misma y también sostiene que la pulsión o instinto del placer es el verdadero motor de la conducta humana.

Ahora bien, la polémica de Lorenz es con Freud. Neodarwinismo contra psicoanálisis $y$, en medio, triturada, la vieja concepción helénica del hombre. Lo natural volvía por sus fueros, pero en más de una versión y planteando agudos antagonismos. Examinemos la cuestión un poco más de cerca.

En El malestar en la cultura, Freud define la felicidad: "lo que en sentido más estricto se llama felicidad surge de la satisfacción, casi siempre instantánea de necesidades acumuladas que han alcanzado elevada tensión". Es, pues, el gozo intenso, el placer instantáneo, no el tibio bienestar. Pero la sociedad no está organizada para proporcionar placer al individuo. Porque el placer sexual -que de él se trata- está mezclado con una buena dosis de agresividad y violencia y de hecho implica un instinto de desintegración y de muerte. El sadismo es el fenómeno en el que se muestra más diáfanamente esa vinculación. Placer y destructividad no son instintos sociales o sociables. Por eso la sociedad se defiende reorientando el sentido de esa energía: "es dirigida contra el propio yo, incorporándose a una parte de éste, que en calidad de super yo 
se opone a la parte restante, y asume la función de conciencia, despliega frente al yo la misma dura agresividad que el yo, de buen grado, habría satisfecho en individuos extraños".

Esta defensa de la sociedad, esta reorientación de la energía placentera se efectúa mediante la cultura, el derecho, la moral, la religión. Estas. instancias suscitan en el individuo deseoso de placer un sentimiento de culpabilidad, de infelicidad. La socialidad sólo puede alcanzarse mediante la progresiva acentuación del sentimiento de culpabilidad. Por eso, el progreso en la cultura "reside en la pérdida de la felicidad por aumento del sentimiento de culpabilidad", en la represión del placer.

La conclusión era devastadora porque las causas de la infelicidad humana no resultaban históricas sino arraigaban en necesidades instintivas. (Dicho sea de paso, Freud define al instinto como "un representante psíquico de los estímulos procedentes del interior del cuerpo que arriban al alma y como una magnitud de la exigencia de trabajo impuesta a lo anímico a consecuencia de su conexión con lo somático". ${ }^{4}$ ) Arraigaban, pues, en la naturaleza biológica y en sus efectos psicológicos.

Ahora bien, una cala de profundidad, en los antecedentes remotos y clásicos de la historia de la filosofía, muestra que el antecedente más. ilustre de Freud es el propio Platón. Recuérdese en el Fedro cómo describe alegóricamente la parte apetitiva del alma. Uno de los corceles del carro del alma "tiene soberbia planta, formas regulares y bien desenvueltas, cabeza erguida y acarnerada; es blanco con ojos negros, ama la gloria con sabio comedimiento; tiene pasión por el verdadero honor; obedece, sin que se le castigue, a las exhortaciones y a la voz de cochero. El segundo tiene los miembros contrahechos, toscos, desaplomados, la cabeza gruesa y aplastada, el cuello corto; es negro, y sus ojos verdes y ensangrentados; no respira sino furor y vanidad; sus oidos velludos están sordos a los gritos del cochero, y con dificultad obedece a las espuelas y al látigo". El corcel apetitivo es obsceno, "se echa, se estira, y, entregándose a movimientos libidinosos, muerde el freno y se atreve a todo con desvergüenza". Las emociones, el sentimiento del valor y deI honor obedecen con facilidad a la razón, que es el cochero, el que dirige el alma, la cual tiene que operar sobre los apetitos como un super yo; al frenar los impulsos el cochero "se echa atrás, como el jinete que va a tocar la barrera y tira con mayor fuerza de las riendas del corcel indómito, rompe sus dientes, magulla su lengua insolente, ensangrienta su boca, le obliga a sentar en tierra sus piernas y muslos y le hace pasar

3 Eigmundo Freud, El malestar en la cultura, Alianza Editorial, Madrid, 1970, pp. 20,64, 74 .

4 Los instintos y sus destinos, en El Malestar en la cultura, p. 137. 
mil angustias". Sólo entonces el caballo negro obedece y, como dice muy elocuentemente Platón, "se muerde de terror".

- Platón dice que originalmente, ontológicamente, por así decirlo, la razón lleva la dirección del alma. Pero eso es en el cielo, en el mundo de las ideas. Aquí abajo dominan los apetitos, el caballo negro corre desalado tras el objeto de su concupiscencia y arrastra tras de si a todo el carro. El hombre no es racional, debiera serlo. Lo es ontológicamente, pero fácticamente no.

Pero, volviendo a lo anterior, el que la estructura instintiva, agresiva, del hombre arraigue en la naturaleza biológica es para nosotros casi como si tuviera fijeza ontológica. Los hombres de principios del siglo $\mathrm{xx}$ heredaron del siglo anterior la creencia de que la naturaleza es un sistema causal, necesario y prácticamente inalterable. Los inconformes buscaban resquicios, "contingencias", como decía Boutroux. Así, cuando Freud arraigó las causas del malestar en la cultura en la estructura impulsiva, instintiva, biológica del hombre, los no resignados buscaron resquicios, pero ya no en las contingencias sino en la historicidad. Herbert Marcuse se preguntó hasta qué punto las causas de la represión no eran biológicas sino históricas. Hasta qué punto una sociedad feliz, no represiva, podía ser el producto de un cambio histórico. $Y$ todavía más, hasta qué punto las necesidades biológicas eran también históricas; y de hecho, sostuvo que la biología del hombre se encuentra transida de historicidad. Pero esta es una pista que no vamos a seguir por ahora.

El otro camino consistía en averiguar si los instintos son como los pintó Freud, y aquí no había más remedio que seguir el camino de la ciencia empírica. Cuando menos uno de ellos, porque tiene muchos.

Lorenz emprende sus investigaciones sobre la agresión animal, como ya lo dijimos, con el deliberado propósito de examinar las afirmaciones de Freud. El que analice a los animales para obtener conclusiones sobre el hombre, está dentro de la mejor tradición darwinista. Se trata de examinar la conducta de los organismos, el del hombre inclusive, sin acudir a la hipótesis de un alma sustancial. Pero ya, en el caso de los neodarwinistas se trata también de averiguar qué ocurre con los mecanismos de la evolución en el terreno de la historia. Esta pregunta había sido desprestigiada antes por el darwinismo social que formuló el mito de racismo con todas las consecuencias que conocemos. Pero entonces se había pasado al extremo contrario y los impulsos biológicos se detenían en los umbrales de la historia para dar paso a los intereses económicos, al afán de poder político a la fuerza de las ideas, a la lucha de clases, etc.

Las discrepancias de Lorenz con Freud están a la vista. En la vida animal encuentra no uno ni dos instintos sino varios y formando un sistema. Cada uno de los instintos aisladamente es rígido, inmutables 
en su forma "como las partes más duras del esqueleto". Pero el sistema es flexible como el esqueleto. Lorenz también utiliza la metáfora del parlamento, el sistema de los instintos es un parlamento en el que cada uno de ellos hace oír su voz. Sólo que unas voces se hacen oír más que otras; hay instintos pequeños al servicio de los cuatro grandes o troncales: los de la alimentación, la reproducción, la fuga y la agresión. Según los estímulos y las situaciones, cada instinto se hace oír y "hace andar a palos a todo el organismo".

Ya hemos mencionado otra característica. También cada uno de esos instintos tiene sus resortes inhibitorios. Un antílope frena su instinto de fuga si tiene que defender a sus crías, una puerca se enfrenta al lobo si tiene que defender a los puerquitos. Un animal feroz frena su instinto de agresividad con sus crías o si anda demasiado lejos de su habitat y tiene posibilidades de fuga, etc.

Pues bien, dentro de estas características funciona el instinto de agresión: sistematicidad, subordinación, inhibición. Y por eso no es desintegrador de la vida sino preservador. La agresión se suscita fundamentalmente para preservar la prole y defender el territorio donde se obtiene el alimento; sin ella, la vida de las especies se habría extinguido ya. Lo que ocurre es que el medio ambiente puede estimular o embotar el cumplimiento de los movimientos instintivos; no los puede suprimir, a menos que suprima la vida. En el caso del hombre, el mundo de los artefactos ha embotado los resortes inhibitorios de la agresión. Un cazador que dispara su escopeta contra una liebre tendría una actividad muy diferente frente a la cacería si tuviera que perseguirla y degollarla con los dientes. Es sustancialmente el mismo caso de las armas nucleares y todas las demás muy sofisticadas; el del cinematográfico hombre que aprieta un botón rojo y desata una guerra atómica.

Esta es la opinión que tiene Lorenz del caballo negro platónico. Se le ha satanizado, es en realidad una instancia de vida. Las exhortaciones de la razón son ineficaces si no están sustentadas en la pulsión de los instintos y tmbién en su certera orientación. El entendimiento puede prever las consecuencias de los actos, pero el instinto es el movimiento mismo. La inminente catástrofe no es culpa de los instintos sino de su desface con la historia. La sociedad tiene que volverse un poco más natural para que se oiga la voz instintiva que nos ha preservado durante tantos millones de años.

Con su opinión, Lorenz habría volteado la tradición al revés. Buena parte de nuestra crisis consistiría no en el predominio de los instintos o lo que se ha llamado bajos apetitos, sino precisamente en lo contrario. Lorenz sabe muy bien que, a pesar de todas las prevenciones de los métodos científicos, nos enfrentamos a la naturaleza con criterios axiológicos 
y que, partiendo de una incorrecta interpretación del darwinismo, la contemplamos como el teatro de una lucha a muerte, cuando que, más bien, esta caracterización le corresponde al mundo histórico, y de una manera radical.

Pero las cosas no se detienen aquí, alguien ha salido a la defensa de las ideas freudianas. Erich From sostiene en su Anatomia de la destructividad humana que a pesar de las minuciosas observaciones etológicas de Lorenz, se concluye con un inmenso equívoco. Pues si bien el etólogo tiene razón cuando subraya el carácter vital de instinto de agresión, los conceptos de Freud sobre el instinto fanático de muerte parecerían más bien referirse a lo que From llama destructividad. "... El hombre, dice Fromm, difiere del animal por el hecho de ser el único primate que mata y tortura a miembros de su propia especie sin razón ninguna, biológica ni económica, y siente satisfacción al hacerlo. Es esta agresión 'maligna', biológicamente no adaptativa y no programada filogenéticamente, la que constituye el verdadero problema y el peligro para la existencia del hombre como especie." 5

Aquí reaparece un concepto de larga tradición en las religiones y en la filosofía. Se trata nada menos que del mal. La destructividad es una agresión, pero maligna, matizada de maldad, especifica del hombre aunque seamos primates. La agresividad es biológica, pero la destructividad no, la maldad no. Ni es económica sino totalmente gratuita. Es esta maldad la que nos pone en peligro como especie. La destrucción del hombre y de su habitación es un peligro que nos proviene del mal, que es animico. Una sonda histórica para encontrar antecedentes nos llevaría muy lejos, puesto que la tradición judeo cristiana de donde proviene este concepto es muy antigua. Detengámonos en un platónico, en San Agustín, quien hace una distinción entre los vicios que nos provienen de la carne y los que nos provienen del ánimo, del alma. Los que pertenecen "al deleite de la carne" son "las fornicaciones, inmundicias, disoluciones, embriagueces y glotonerías". También hay "los vicios del ánimo que son ajenos al deleite carnal; porque: ¿Quién hay que ignore que la idolatría, las hechicerías, las enemistades, rivalidades, celos, iras, disensiones, herejías y envidias son vicios del espíritu más que de la carne?" 6

La ira, las enemistades, las rivalidades, provienen del ánimo, son demoníacos, porque es el demonio el que provee los vicios aunque no

5 Erich Fromm, Anatomía de la destructividad humana, Siglo XXI Editores, México, 1977, p. 19.

6 San Agustín, La ciudad de Dios, tomo II, Editorial Poblet, Buenos Aires, 1942 , p. 4. 
tenga cuerpo y con más razón los que no son corporales, dice Agustín con palabras que tienen un inmenso eco en la historia.

Detengamos aquí la exposición y veamos qué hay del problema que nos habíamos planteado al principio. En primer término cabe examinar cómo se presentan, en este ejemplo, las llamadas explicaciones externas del filosofar, es decir, las vinculaciones que unen al filosofar con la circunstancia en la cual se inserta el filósofo. Hemos utilizado antes las palabras suscitar, determinar y condicionar. Creo que, en el ejemplo, la existencia real del peligro de la desaparición del hombre suscita el filosofar, pero no lo determina. No hay, por así decirlo, determinación causal. No se puede, en rigor, decir que dados determinados fenómenos sociales A se da un tipo de filosofar B; sino que un tipo de fenómeno $A$ suscita, provoca, estimula, tipos de filosofar B, C, D, ... indeterminadamente. Dijimos que el ejemplo estaba escogido a propósito. Se trata de un ejemplo singular pues el peligro de la desaparición del hombre por obra de sus artefactos se da por primera vez en la historia. Pero este peligro suscita diversos tipos de filosofar: Lorenz habla de un desface entre instintos e historia, From habla de una maldad anímica. Otros lo considerarían como un riesgo no controlado en el conflicto de los intereses económicos y políticos, algo así como el resultado de un descuido.

De manera que si, como decía Husserl, nos atenemos a lo que se da y sólo a lo que se da, no podemos hablar de una determinación. Tampoco de un reflejo; ni la más mínima de las teorías experimentales puede ser considerada un reflejo de lo que se da, mucho menos elaboraciones teóricas tan complicadas como la filosofía y la ciencia que son interpretaciones de los acontecimientos.

Se habla también de la capacidad expresiva de la filosofía; que ella expresaría la situación-hombre que la emite. Por ejemplo, que una situación enajenante produce un filósofo enajenado, el cual fabrica a su vez una filosofía enajenada, sea lo que sea semejante cosa. El filósofo "traduciría" la situación enajenada fabricando una teoría enajenada. Se trata en realidad de una concresión del argumento determinista, causal; el problema está en las reglas de esta traducción, cómo probar, puesto que de esto se trata, que a un determinado rasgo enajenante corresponde un concepto teórico enajenante y que tal rasgo así y sólo así puede ser traducido a la teoría. Aparte del hecho mayúsculo de que los enajenados, que se benefician con la enajenación, también pueden denunciarla, como en el caso sobresaliente de Herbert Marcuse. En realidad, lo que 
ocurre es que un tipo de fenómenos, a los cuales se califica de enajenantes, funcionando como estímulos, provocan una serie de teorías cuya variedad no puede ser prevista. Cuando menos esto es lo que se desprende del ejemplo analizado. Lorenz y Fromm acuden a sus respectivas explicaciones y abandonan economicismos y politicismos porque encuentran un tipo de violencia que ellos califican de gratuita y buscan su origen o en los instintos o en la maldad. Pero no puede decirse que esa violencia sea la causa de las peculiaridades de sus teorías.

Esto es, por así decirlo lo que atañe a las dimensiones histórico sociales. Veamos lo que ocurre específicamente con el pasado histórico. Cuando los pensadores contemporáneos enuncian ideas sobre cuestiones fundamentales de la filosofía siempre se transparentan en ellas los clásicos. Las calas hasta la filosofía platónica o a la agustiniana están claramente propiciadas en los enunciados que hemos reseñado. ¿Se trata de meros antecedentes? Creo más bien que se trata de sus condiciones de posibilidad. Cuando se habla de la historicidad de la filosofía se señala casi siempre su acentuado carácter cambiante. Pero poco se dice que la historicidad consiste también, y mucho, en la acumulación de pasado, de experiencia teórica. La experiencia filosófica y científica nos impide filosofar como Tales de Mileto. La capacidad crítica de la filosofía y el pensamiento científico indican que muchas de las soluciones del pasado son ya vías muertas que no conducen a ninguna parte, aunque en su tiempo hayan sido fecundas. $Y$ al revés, señalan la vigencia de muchos planteamientos. Una discusión sobre el papel de la razón, sobre los instintos y el mal no puede dejar de lado ni a Platón, ni a San Agustín, ni a Darwin ni a Freud. No podemos teorizar sobre el asunto como si ellos no lo hubiesen hecho nunca. La historicidad, como decía Ortega y Gasset, consiste en que no estrenamos la humanidad, como un tigre sí estrena su tigridad. Lo hecho por los otros en el pasado pone las condiciones de posibilidad de los que hagamos nosotros. La experiencia teórica condiciona nuestras respuestas teóricas a los temas suscitados por el entorno. $\mathrm{Y}$ hablo de condiciones de posibilidad porque tampoco hay determinación en este caso. Frente a las cuestiones fundamentales, la experiencia filosófica proporciona siempre alternativas, como se ve claramente en la discrepancia Lorenz-Froom.

Por otra parte, esas alternativas casi nunca son muchas. En primer término, porque el carácter cambiante de la historia no es absoluto, si lo fuera, el pasado nos sería totalmente ajeno. En el caso que nos ocupa se pueden advertir estructuras bastante permanentes; en el caso de la explicación de la naturaleza humana, que es el que nos ocupa, el dualismo atraviesa toda la historia de la filosofía, cuando menos de Platón a Fromm. Claro, a veces puede ser un dualismo sustancial, como en 
el caso de Platón o Descartes y a veces, aunque no sea sustancial, también es dualismo. Los etólogos quieren ganar una concepción unitaria de la naturaleza humana extendiendo la frontera de la animalidad, pero aun así la explicación se mueve entre los instintos y el pensamiento conceptual, aunque conciban al pensamiento conceptual también como de origen natural.

I a permanencia de estructuras básicas se debe, por una parte, a las necesidades del pensamiento teórico, es decir, el que aspira a pruebas argumentales o empíricas. Y por otra, a la naturaleza misma de los objetos de que se ocupa. El mundo no es el río heraclitano que se transforma en una vertiginosa corriente, al menos no lo es en las dimensiones humanas. El corazón del siglo xvi es el mismo que el del siglo xx y la inmundicia agustiniana es también nuestra inmundicia. Esto se verá con más claridad si comparamos la verdad científica con la verdad filosófica. No en vano escogimos un ejemplo de la ciencia.

Las conclusiones de Lorenz están fundadas en el análisis de una multiplicidad de experiencias y observaciones. Se ha pasado toda su vida siguiendo la pista de los animales. Incluso ha elaborado cuadros formalizados de los gestos de ciertos animales que tienen relaciones horizontales, verticales y diagonales. Sus conclusiones sobre la génesis, estructura y funcionamiento de los instintos han hecho avanzar a la etología, la biología y la psicología. ¿Cuándo se convierte en filósofo? Cuando totaliza y da un salto mortal y de la explicación del galanteo de los gansos pasa a opinar sobre las relaciones entre lo natural y lo histórico. En este salto está la clave de la diferencia de historicidad entre la ciencia y la historia.

Los etólogos y los zoólogos saben cada vez más sobre el galanteo de los gansos porque se trata de un fenómeno reiterado y susceptible de experimentación. Además, los bioquímicos aportan más noticias cada vez sobre la doble hélice (ácido desoxirribonucleico). La historicidad de la ciencia es progresiva, su cambio es progresivo aunque no siempre se trate de un progreso lineal. Pero si reflexionamos un poco sobre la afirmación filosófica nos sale al paso una interrogación: ¿cómo verificamos que los instintos no han tenido tiempo para adaptarse al ritmo de la historia producido por el pensamiento conceptual y la palabra? El problema es de tiempo porque los principales procesos de adaptación son de larguísima duración. Además habría que precisar las diferencias concretas entre tiempo biológico y tiempo histórico. Sin embargo, la afirmación de Lorenz si se funda _-aunque sea un fundamento insuficiente- en un dato observable: la obliteración de los resortes inhibitorios de la agresión en la vida humana. Es un punto de partida empírico para una afirmación cuya generalidad tiene muy pocos fundamentos empíricos. El pro- 
cedimiento empírico de las ciencias acarrea un resultado progresivo porque se trata de un examen de fenómenos reiterados susceptibles de muchas observaciones que acumulan información. En cambio, la filosofía se constituye de afirmaciones tan generales que los fundamentos empíricos siempre son insuficientes - cuando existen. De allf la variedad, más que la acumulación progresiva, de opiniones filosóficas. Por eso, algunas filosofías contemporáneas fuertemente influidas por la ciencia empírica tienen proclividad a la teoría del conocimiento, porque el conocimiento siempre está ahí, puede ser analizado como un fenómeno empírico, o es un fenómeno empírico.

Ahora bien, este grado de generalidad de la filosofía no le resta valor porque sin ello el desarrollo del conocimiento, y a veces de la acción, carecería de orientación. Históricamente es perfectamente demostrable que la filosofía ha abierto amplias áreas del conocimiento a las posteriores ciencias empíricas, como, por ejemplo, la filosofía de la historia se la abrió a la sociología —en mi opinión todavía va un paso más adelante. Para no mencionar las cuestiones éticas y políticas o las metafísicas. De aquí, pues, que la diferencia de objetos, unos empíricos, y otros que no lo son propiamente, determine una diferencia de dinámica, de historicidad.

Pasemos a las necesidades del pensamiento teórico. Veamos específicamente el caso de la vinculación entre el tratamiento histórico de la filosofía y su tratamiento sistemático. $Y$ veámoslo en nuestro ejemplo. El objeto condiciona que la mayoría de las explicaciones sobre la naturaleza humana sean dualistas, pero su dinámica prosigue porque la lógica, aquella parte de la filosofía que analiza los argumentos, mostró, cuando menos desde la época de Aristóteles, que esta solución dualista tenia una falla argumentativa. Aristóteles, criticando a Platón, lo denominó como el problema de la participación, la participación de los objetos materiales en su Idea, que no es material y que está fuera de la caverna. Idéntico problema se le planteó a Descartes para conciliar la substancia extensa y la substancia pensante. Entonces se habló de una armonía preestablecida.

Pues bien, este problema sigue acechando a toda solución dualista, aunque el dualismo no sea sustancial. Se puede ver claramente cómo aqueja a Lorenz y a Fromm. Entonces, si alguien quisiera terciar en su polémica se encontraría con una luz roja que le da indicaciones desde el pasado filosófico. El pasado filosófico no sólo aporta soluciones sino también indicaciones críticas como la que hemos mencionado o como la celebérrima crítica de Kant a las argumentaciones ontológicas sobre la existencia de Dios.

Se ha atacado en este coloquio a la historia de la filosofía como cró- 
nica filosófica. Pero una crónica de las principales críticas que se han dado a las más importantes tesis, no le sería indiferente a quien quiera tratar sistemáticamente a la filosofía, esto es, al que averigüe sobre su verdad o falsedad. $Y$ no sólo sería pertinencia, sería también condicionamiento. Denunciaría falsas salidas y dejaría un callejón muy estrecho para transitar a quien quiera argumentar y probar sus filosofemas. Quien no quiera hacerlo puede tomar el camino real de la imaginación desbocada. 